Health Informatics- An International Journal (HIIJ) Vol.2,No.4,November 2013

\title{
RANKING THE MicRo LeVEl CRITICAL FACTORS OF ELECTRONIC MEDICAL RECORDS ADOPTION USING TOPSIS METHOD
}

\author{
Hossein Ahmadi ${ }^{1}$, Maryam Salahshour Rad ${ }^{2}$, Mehrbakhsh Nilashi $^{3, *}$, Othman \\ Ibrahim $^{4}$, Alireza Almaee ${ }^{5}$ \\ 1,2,3,4 Faculty of Computing, Universiti Technologi Malaysia, Johor, Malaysia \\ ${ }^{5}$ Department of Management, Rasht Payame Noor University, Rasht, Iran
}

\begin{abstract}
In many countries, the health care sector is entering into a time of unprecedented change. Electronic Medical Record (EMR) has been introduced into healthcare organizations in order to incorporate better use of technology, to aid decision making, and to facilitate the search for medical solution. This needs those professionals in healthcare organizations to be in the process of changing from the use of paper to maintain medical records into computerized medical recordkeeping opportunities. However, the adoption of these electronic medical records systems has been slow throughout the healthcare field. The critical users are physicians which play an important role to success of health information technology including Electronic Medical Record systems. As a result user adoption is necessary in order to understand the benefits of an EMR. Therefore, in the current paper, a model of ranking factors of micro-level in EMRs adoption was developed. Surveys distributed to physicians as this study's respondent in two private hospitals in Malaysia. The findings indicate that physicians have a high perception means for the technology and showed that EMR would increase physician's performance regarding to decision making. They have been and continue to be positively motivated to adopt and use the system. The relevant factors according to micro-level perspective prioritized and ranked by using the Technique for Order of Preference by Similarity to Ideal Solution (TOPSIS). The aim of ranking and using this approach is to investigate which factors are more important in EMRs adoption from the micro-level perspectives. The results of performing TOPSIS is as a novelty which assist health information systems (HIS) success and also healthcare organizations to motivate their users in accepting of new technology.
\end{abstract}

\section{KEYWORDS}

EMRs, Adoption, TOPSIS, Micro-Level Adoption Factors

\section{INTRODUCTION}

The health care industry's growing adoption of Electronic Medical Records (EMR) is becoming a new perspective on the role of healthcare professionals. Information technology has been proved to be as an imperative element in the administration of healthcare [34]. In particular, some private hospitals in Malaysia are adopting information systems that offer more accurate and timely information concerning patient care [5]. By utilizing information technology hospitals are capable to retain documentation of their daily transactions such as in data storage, retrieving and communication. Currently, the midst of a landmark shift in record keeping, with driving for electronic medical records well in progress [6]. An EMR system was introduced as a way to make possible a centralized patient information repository. For many purposes EMR is utilized

DOI: 10.5121/hiij.2013.2402 
including administration, patient care, quality improvement, research, and reimbursement [35]. These applications need knowledge of the underlying quality of the data within the EMR so as to avoid misinterpretation [35]. EMRs would remedy the intrinsic flaws of the conventional paper system through improvements in accessibility, efficiency, quality of data capture and cost saving. As a result, an EMR system should be able to appropriately capturing, processing and storing information and also should be compatible with other related systems [6]. It affects the quality outputs in health care provider which users by using the patient information can be able to make decisions. By increasing the accuracy of patient information, it is possible to less likely that they face large differences in errors and consequently decreases the marginal revenue from quality growing [6].

In relation with EMR, the concept of clinical system places reduction of medical error into the wider context of quality of care and safety by giving a framework to evaluate and assess the structure, process and outcomes of care. The purpose of this paper is to describe the factors that have more priority in affecting EMR to adopt in private hospitals in Malaysia. The critical elements of this paper include HIS quality, use and net benefits with their sub-factors.

The remainder of this paper is structured as follows. Section 1 describes the EMR and gives an overview of this research. The section 2 introduces the proposed research model. In Section 3, we explain the research methodology step by step. Section 4 and 5 are allocated to the background mathematical of The Technique for Order of Preference by Similarity to Ideal Solution (TOPSIS) and data collection, respectively. Finally, we present the results of TOPSIS and conclusions in sections 6 and 7, respectively.

\section{PROPOSED RESEARCH MODEL}

The physician adoption model provides a conceptual model to identify the factors that have more influence on health information systems (HIS) success. It extends Info way Benefits Evaluation (BE) Framework [18] (adapted from the DeLone and McLean information system success model [9] which Thereafter, [12] in his study review developed Clinical Adoption (CA) framework based on three dimensions. The framework comprised of micro, meso and macro-level dimensions. Each dimension has its own factors and sub-factors which could affect physicians in EMR adoption. In this study it has been focused on micro-level factors. Physician adoption model at the micro-level explains HIS success related to HIS quality, use and net benefits. HIS quality divided in information, system and service quality respectively; use covers HIS usage and satisfaction; net benefits covers care quality, access, and productivity. The physician adoption model was developed with a range of HIS in mind, including EMRs. In this review, we examined EMR and its success in health centre thru the lens of the physician adoption model. EMR adoption has been described and influence on physician practice, according to evaluation measures utilized in the studies. In regarding of Factors that have been caused to this impact, it has been described as the reasons cited that could explain the adoption and effect. Hence, in this study we have concentrated on Micro level factors that affects on EMR adoption. At the end the proposed model has been developed and shown in Figure 1.

It has been required for system quality to sustain high quality health service delivery that meets the request of the people. System quality affects the quality of care by capturing, transferring, storing, managing and displaying medical information. In growing the quality of these processes, the system should give higher quality (12).

System quality factors included the availability of templates [2], interface design [6, 12], Newby [36] and technical performance (e.g. speed and reliability) [24, 35]. 
Information quality plays a critical role in hospital. The organization, accuracy, completeness and accessibility of the patient record are the sub factors of information quality $[1,6,11,12,13,24$, 27].

Service quality is a comparison of expectations with performance. Health care provider with high service quality will meet patient needs whilst remaining economically competitive. Improved quality may increase economic competitiveness. If patients who have not been satisfied with preferred hospitals can deliver quality services, they would look for the services elsewhere. Thus it is imperative to inquire patients in a straight line about the perceived quality of services provided by the country's hospitals [31]. Service quality factors included training and technical support [32,38] system backup and unexpected downtime [31].

Electronic medical records usage can differ depending on how they utilize it and who the user is. Electronic medical records would assist to advance the quality of medical care given to patients. Removing the traditional paper records are denied by Many doctors and office-based physicians [22]. Factors in EMR usage covers its intent (e.g. quality improvement versus record keeping) [21], actual strategies for optimal use, ease of use [11, 29] and usage patterns that appeared gradually [17]. The relevant factors of interaction included patient-physician encounters like patients' ability to schedule appointments [10], the kind of consult (e.g. psychological) [3, 22, 23], and consult room layout [22].

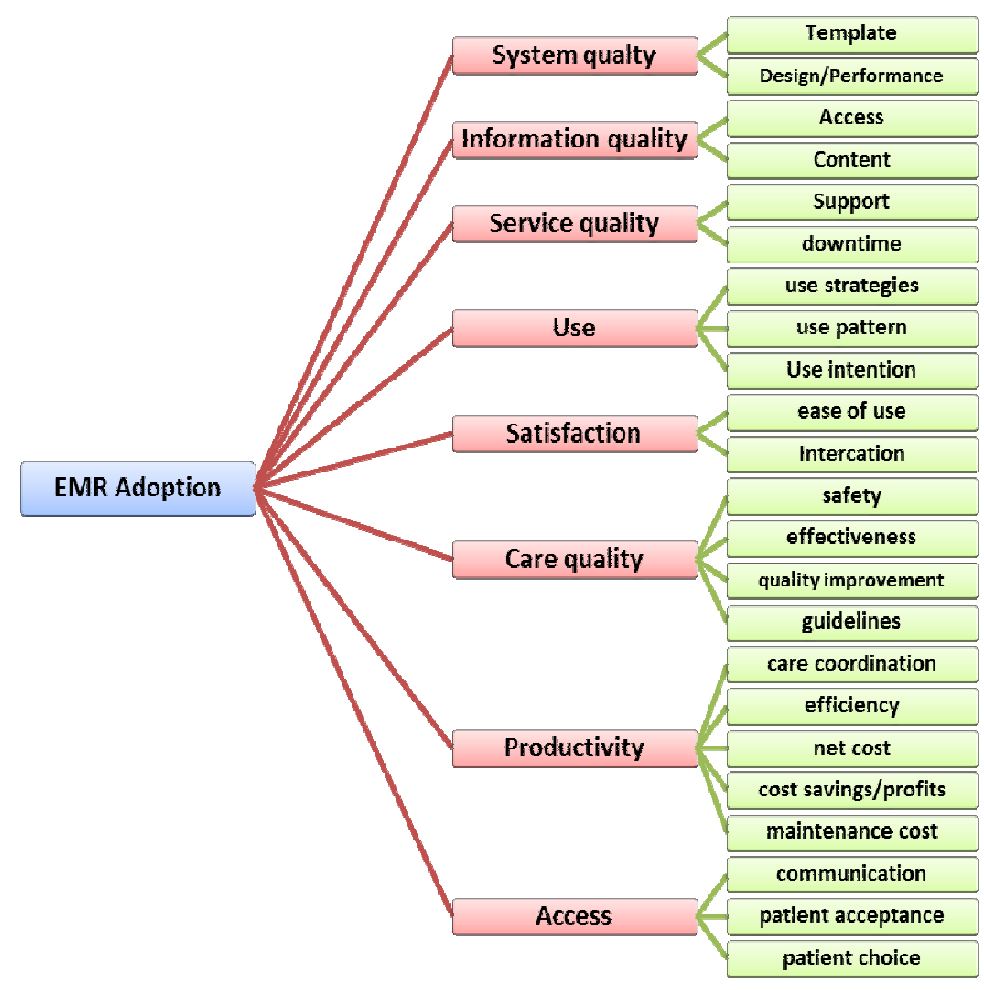

Figure 1. TOPSIS Framework of Physician Adoption Model in Micro-Level

Net benefits, care quality factors covered patient safety [14], care effectiveness [17], quality improvement [27] and guideline compliance [8, 36]. Productivity factors covered care efficiency $[14,33]$, coordination [35], and net cost including billing, staffing and maintenance costs [2, 27, $24,31]$. 
Micro-level factors that found in previous research which has an effect on EMR adoption and effect were shown (See Table 1).

Table 1.Micro -level factors that influenced EMR success

\begin{tabular}{|l|l|l|}
\hline HIS quality & HIS quality sub-factors & References \\
\hline \multirow{3}{*}{ System quality } & Template & {$[2,22]$} \\
\cline { 2 - 3 } Information & Design/performance & {$[6,12,21,24,28,30,35,37]$} \\
\cline { 2 - 3 } quality & Access & {$[6]$} \\
\cline { 2 - 3 } Service quality & Content & {$[1,6,11,12,13,24,27,28,33,35,37]$} \\
\cline { 2 - 3 } & Dupport & {$[32,38,39]$} \\
\hline HIS Use & HIS quality Sub-factors & {$[31,38]$} \\
\hline \multirow{4}{*}{ Use } & References \\
\hline \multirow{4}{*}{ Satisfaction } & Use ptrategies & {$[3]$} \\
\cline { 2 - 3 } & Use intention & {$[17]$} \\
\hline Net benefits & Ease of use & {$[21]$} \\
\cline { 2 - 3 } Care quality & Interaction & {$[11,29]$} \\
\hline \multirow{5}{*}{ Productivity } & Set benefits Sub-factors & {$[3,6,22,23]$} \\
\cline { 2 - 3 } & Effectiveness & Refences \\
\cline { 2 - 3 } & Quality improvement & {$[14]$} \\
\cline { 2 - 3 } & Guidelines & {$[27]$} \\
\hline & Care coordination & {$[8,27,36]$} \\
\cline { 2 - 3 } & Efficiency & {$[2,35]$} \\
\cline { 2 - 3 } & Net cost & {$[16,4,14,33]$} \\
\cline { 2 - 3 } & Cost Savings/Profits & {$[2,27]$} \\
\cline { 2 - 3 } & Maintenance cost & {$[27]$} \\
\hline \multirow{5}{*}{ Access } & Communication & {$[31]$} \\
\cline { 2 - 3 } & Patient acceptance & {$[4]$} \\
\cline { 2 - 3 } & Patient choice & {$[10]$} \\
\hline
\end{tabular}

\section{RESEARCH METHODOLOGY}

Researcher covered the topic of Electronic Medical Record adoptions shown that EMR are being accepted by private hospital of Malaysia. A quantitative, survey-based research study was performed and was analysed to explaining the factors that have an effect on EMR adoption. The two hospitals have been chosen to conduct this research. Survey distributed to 150 physicians who had experience using EMRs. 90 physicians fulfilled the questionnaire in this study and the rest did not complete the survey study because of their time constrain. The survey contains number of questions that were design to capture information about the constructs in the research model. The questions that measured were HIS quality, HIS use and net benefits besides their subfactors. TOPSIS was use to obtain the ranking of these factors. Figure 2 contains a description of each step in this study. 
Health Informatics- An International Journal (HIIJ) Vol.2,No.4,November 2013

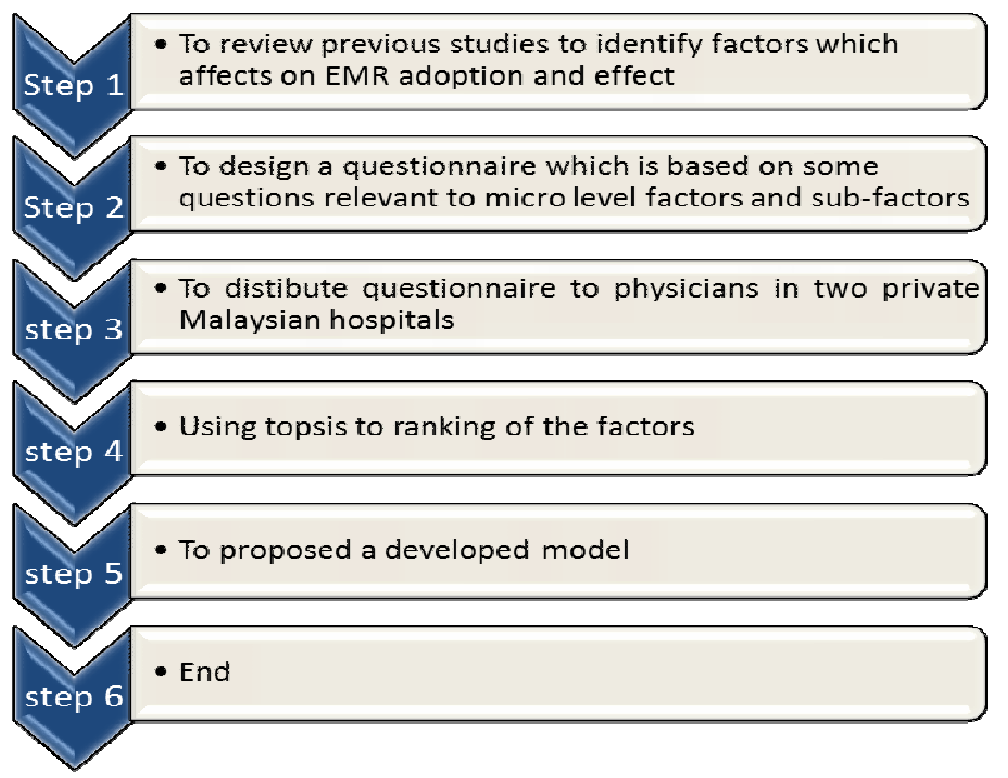

Figure 2. Research methodology

\section{MATHEMATICAL BACKGROUND OF TOPSIS}

TOPSIS is one of the famous classical Multi-Criteria Decision Making (MCDM) method, which was initiated for the first time by Hwang and Yoon [40] that shall be used with both normal numbers and fuzzy numbers $[41,42]$. Furthermore, TOPSIS is more applicable in that limited subjective input is required from decision makers. The only subjective input required is weights. The TOPSIS procedure is shown in Figure 3 in five main steps.

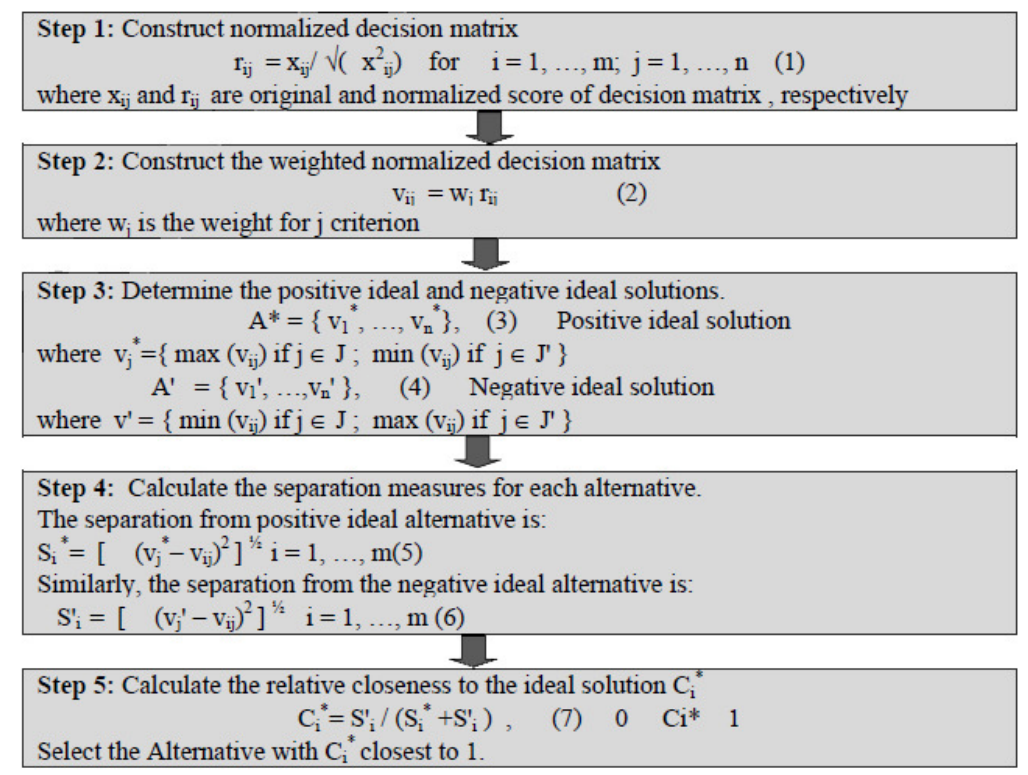

Figure 3. Procedure of TOPSIS method 
Using entropy method, objective weights were calculated. The following equation calculates entropy measure of every index.

$$
E_{j}=-K \sum_{i=1}^{m}\left[n_{i j} \operatorname{Ln}\left(n_{i j}\right)\right] \Rightarrow\left\{\begin{array}{l}
\forall_{j}=1,2, \ldots n \\
K=\frac{1}{\operatorname{Ln}(m)}
\end{array}\right\}
$$

The degree of divergence $d_{j}$ of the intrinsic information of each criterion $C(j=1,2, \ldots, n)$ may be calculated as

$$
d_{j}=1-E_{j}
$$

The value $d_{j}$ represents the inherent contrast intensity of $c_{j}$. The higher the $d_{j}$ is, the more important the criterion $c_{j}$ is for the problem. The objective weight for each criterion can be obtained. Accordingly, the normalized weights of indexes may be calculated as

$$
W_{j}=\frac{d_{j}}{\sum_{k=1}^{n} d_{k}}
$$

\section{DATA COLLECTION}

The primary data in this study were collected through questionnaire that distributed to the physicians through web based questionnaire who have some experiences in using EMR. For this study, a number of respondents, were approximately $150(n=150)$ physicians. Sixty percent $(60 \%)$ of the respondents provided answers to all the questions in the instrument.

The first section comprise of information on respondent demographic profile, eightsections on the independent variable namely, system quality, information quality, service quality, use, satisfaction, care quality, productivity and access. Five options (index) ranked by $1-5$ (1= very low important $2=$ low important $3=$ moderately important $4=$ high important $5=$ very high important) were used for the raised questions. 
Health Informatics- An International Journal (HIIJ) Vol.2,No.4,November 2013

Table 2. The respondents' demographic profile

\begin{tabular}{|l|l|l|l|}
\hline Aspects & Category & Respondents (n) & Respondents (\%) \\
\hline Gender & Male & 75 & $75 \%$ \\
\hline \multirow{2}{*}{ Age } & Female & 25 & $25 \%$ \\
\hline & $26-33$ & 20 & $13.4 \%$ \\
\hline & $34-50$ & 45 & $30 \%$ \\
& $51-65$ & 85 & $56.6 \%$ \\
\hline \multirow{2}{*}{$\begin{array}{l}\text { Years of electronic medical } \\
\text { records experience }\end{array}$} & $1-5$ & 54 & \\
\cline { 2 - 4 } & $6-10$ & 15 & $56.8 \%$ \\
\cline { 2 - 4 } & Over 10 & 3 & $3.2 \%$ \\
\hline Medical specialization & Generalist & 68 & $67 \%$ \\
\cline { 2 - 5 } & Specialist & 34 & $33 \%$ \\
\hline
\end{tabular}

Table 2 provides the respondents' demographic profile. About seventy five percent of physicians were male and twenty five percent were female, generalist and specialist physicians in with one to five years of experience with Electronic Medical Records technology.

\section{RESULTS OF TOPSIS}

In this section, we provide the results of TOPSIS for ranking the factors presented in the TOPSIS Framework of physician adoption model in micro-level. According to the Figure 1, the aim of applying TOPSIS is to rank the 23 factors to show the importance of these factors in EMRs adoption in micro-level.

In addition, based on five steps of TOPSIS shown in Figure 3 and formulas presented in equations 1, 2 and 3, we calculated the weights of five indices as following:

$$
\begin{array}{ll}
\mathrm{E}_{1}=-\mathrm{k} \sum_{\mathrm{i}=1}^{\mathrm{m}}\left(\mathrm{n}_{\mathrm{ij}} \ln \left(\mathrm{n}_{\mathrm{ij}}\right)\right)=-3.26 & \mathrm{E}_{2}=-\mathrm{k} \sum_{\mathrm{i}=1}^{\mathrm{m}}\left(\mathrm{n}_{\mathrm{ij}} \ln \left(\mathrm{n}_{\mathrm{ij}}\right)\right)=-4.13 \quad \mathrm{E}_{3}=-\mathrm{k} \sum_{\mathrm{i}=1}^{\mathrm{m}}\left(\mathrm{n}_{\mathrm{ij}} \ln \left(\mathrm{n}_{\mathrm{ij}}\right)\right)=-2.68 \\
\mathrm{E}_{4}=-\mathrm{k} \sum_{\mathrm{i}=1}^{\mathrm{m}}\left(\mathrm{n}_{\mathrm{ij}} \ln \left(\mathrm{n}_{\mathrm{ij}}\right)\right)=-2.29 & \mathrm{E} 5=-\mathrm{k} \sum_{\mathrm{i}=1}^{\mathrm{m}}\left(\mathrm{n}_{\mathrm{ij}} \ln \left(\mathrm{n}_{\mathrm{ij}}\right)\right)=-3.25
\end{array}
$$

Thus, using Entropy method, the weights are obtained as:

$$
\begin{aligned}
& \mathrm{w}_{1}=\boldsymbol{0 . 2 3 6} \\
& \mathrm{w}_{2}=\mathbf{0 . 2 2 0} \\
& \mathrm{w}_{1}=\mathbf{0 . 1 7 8} \\
& \mathrm{w}_{4}=\mathbf{0 . 1 6 8} \\
& \mathrm{w}_{5}=\mathbf{0 . 1 9 6}
\end{aligned}
$$

where

$$
\sum w_{i}=1 \Rightarrow w_{1}+w_{2}+w_{3}+w_{4}+w_{5}=1
$$


Health Informatics- An International Journal (HIIJ) Vol.2,No.4,November 2013

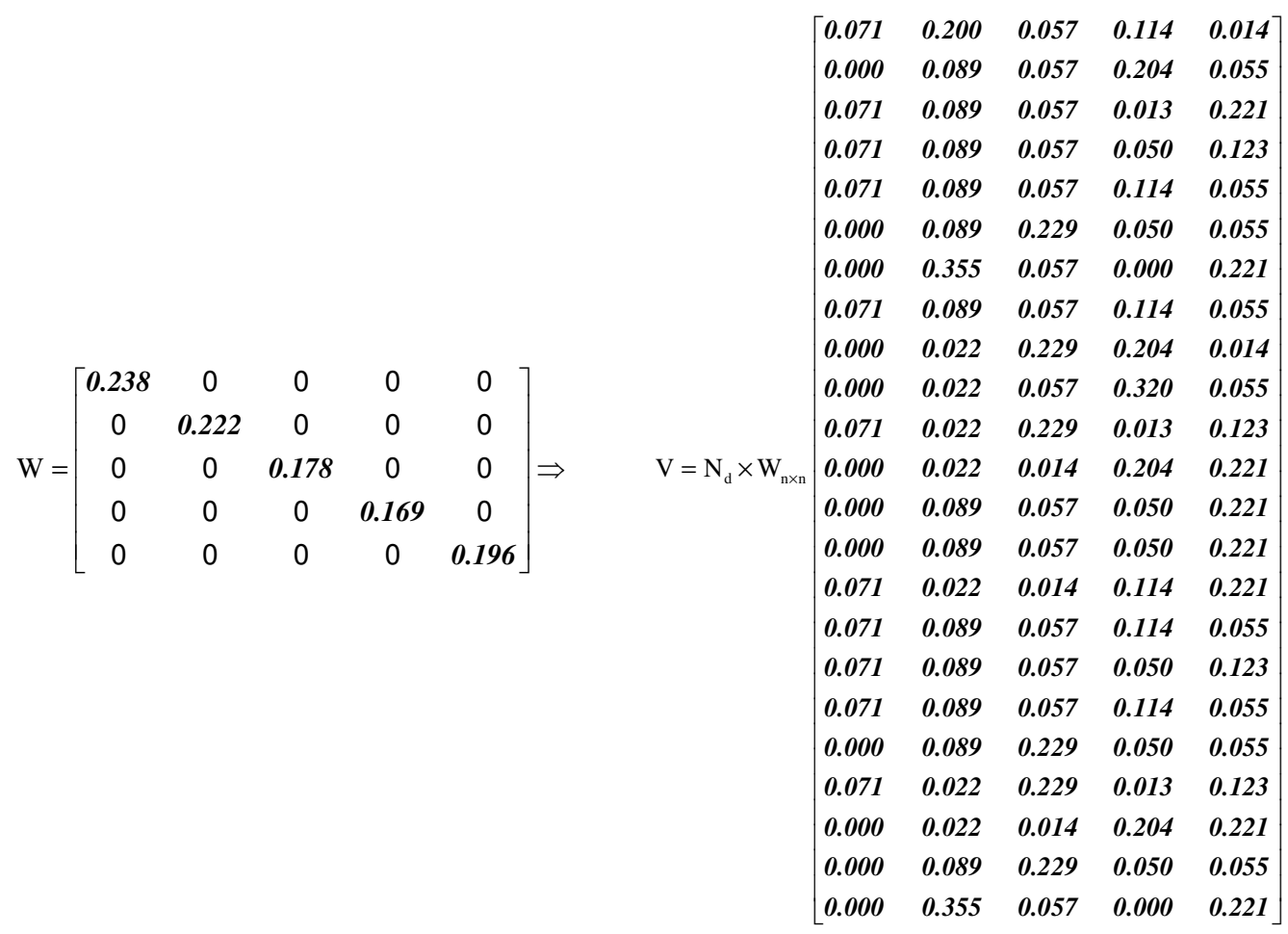

and where $\mathrm{N}_{\mathrm{d}}$ denotes the normalized ratings of responses' participants and $\mathrm{V}$ denotes the nonscaled weight matrix.

According to the third step of TOPSIS shown in Figure 1, we calculated the positive and negative ideals as following:

Positive Ideal $=\mathrm{A}+=\left\{\left(\max \mathrm{V}_{\mathrm{ij}}\right),\left(\max \mathrm{V}_{\mathrm{ij}}\right), \mathrm{i}=1,2, \ldots, \mathrm{m}\right\}=\left\{\mathrm{V}_{1}+, \mathrm{V}_{2}+, \ldots \mathrm{V}_{\mathrm{n}}+\right\}$

Table 3. Positive ideal

\begin{tabular}{c|c|c|c|c}
\hline Max $\mathbf{V}_{\text {i1 }}$ & Max $\mathbf{V}_{\mathbf{i} 2}$ & Max $\mathbf{V}_{\mathbf{i} 3}$ & $\operatorname{Max} \mathbf{V}_{\mathbf{i} 4}$ & $\operatorname{Max} \mathbf{V}_{\mathbf{i} 5}$ \\
\hline 0.071 & 0.355 & 0.229 & 0.204 & 0.221 \\
\hline
\end{tabular}

Negative Ideal $=\mathrm{A}^{-}=\left\{\left(\operatorname{minx} \mathrm{V}_{\mathrm{ij}}\right),\left(\min \mathrm{V}_{\mathrm{ij}}\right), \mathrm{i}=1,2, . ., \mathrm{m}\right\}=\left\{\mathrm{V}_{1-}, \mathrm{V}_{2-}-, \ldots \mathrm{V}_{\mathrm{n}^{-}}\right\}$ 
Table 4.Negative ideal

\begin{tabular}{ccccc}
\hline Min $\mathbf{V}_{\mathbf{i} 1}$ & Min $\mathbf{V}_{\mathbf{i} 2}$ & $\operatorname{Min} \mathbf{V}_{\mathbf{i} 3}$ & $\operatorname{Min} \mathbf{V}_{\mathbf{i} 4}$ & $\operatorname{Min} \mathbf{V}_{\mathbf{i} 5}$ \\
0 & 0.022 & 0.014 & 0 & 0.014 \\
\hline
\end{tabular}

As shown in the Table 3 and Table 4, we selected the maximum and the minimum of each column of matrix $\mathrm{V}$ as positive and negative ideals. Thus, $\mathrm{A}+$ and $\mathrm{A}$ - denote all the maximum and minimum numbers of each column of matrix $\mathrm{V}$.

For step 4 of TOPSIS procedure, we calculate the distance i from positive ideal as following:

Distance i from positive Ideal $=\left\{\sum_{j=1}\left(v_{i j^{-}}-v_{j^{+}}\right)^{2}\right\}^{1 / 2}$

Table 5 presents the distance i from positive ideal for 23 factors. In this table, the square of difference between distance between max point and each point ideal are provided.

Table 5. Distance i from positive ideal

\begin{tabular}{ccccc}
\hline$\left(v_{i j^{-}} v_{j+}\right)^{2}$ & $\left(v_{i j}{ }^{-} v_{j+}\right)^{2}$ & $\left(v_{i j}{ }^{-} v_{j+}\right)^{2}$ & $\left(v_{i j^{-}} v_{j+}\right)^{2}$ & $\left(v_{i j^{-}} v_{j+}\right)^{2}$ \\
\hline 0.00000 & 0.02413 & 0.02965 & 0.00802 & 0.04299 \\
0.00504 & 0.07089 & 0.02965 & 0.00000 & 0.02768 \\
0.00000 & 0.07089 & 0.02965 & 0.03630 & 0.00000 \\
0.00000 & 0.07089 & 0.02965 & 0.02357 & 0.00962 \\
0.00000 & 0.07089 & 0.02965 & 0.00802 & 0.02768 \\
0.00504 & 0.07089 & 0.00000 & 0.02357 & 0.02768 \\
0.00504 & 0.00000 & 0.02965 & 0.04162 & 0.00000 \\
0.00000 & 0.07089 & 0.02965 & 0.00802 & 0.02768 \\
0.00504 & 0.11077 & 0.00000 & 0.00000 & 0.04299 \\
0.00504 & 0.11077 & 0.02965 & 0.01339 & 0.02768 \\
0.00000 & 0.11077 & 0.00000 & 0.03630 & 0.00962 \\
0.00504 & 0.11077 & 0.04614 & 0.00000 & 0.00000 \\
0.00504 & 0.07089 & 0.02965 & 0.02357 & 0.00000 \\
0.00504 & 0.07089 & 0.02965 & 0.02357 & 0.00000 \\
0.00000 & 0.11077 & 0.04614 & 0.00802 & 0.00000 \\
0.00000 & 0.07089 & 0.02965 & 0.00802 & 0.02768 \\
0.00000 & 0.07089 & 0.02965 & 0.02357 & 0.00962 \\
0.00000 & 0.07089 & 0.02965 & 0.00802 & 0.02768 \\
0.00504 & 0.07089 & 0.00000 & 0.02357 & 0.02768 \\
0.00000 & 0.11077 & 0.00000 & 0.03630 & 0.00962 \\
0.00504 & 0.11077 & 0.04614 & 0.00000 & 0.00000 \\
0.00504 & 0.07089 & 0.00000 & 0.02357 & 0.02768 \\
0.00000 & 0.00000 & 0.02965 & 0.04162 & 0.00000 \\
\hline & & & &
\end{tabular}

Similar to distance $\mathrm{i}$ from positive ideal, we calculate the distance $\mathrm{i}$ from negative ideal as following: 
Distancei from negative Ideal $=\left\{\sum_{j=1}\left(v_{i j^{-}}-v_{j-}\right)^{2}\right\}^{1 / 2}$

Table 6 presents the distance i from negative ideal for 23 factors. In this table, the square of difference between distance between min point and each point are provided.

Table 6. Distance i from negative ideal

\begin{tabular}{ccccc}
\hline$\left(v_{i j} v_{j+}\right)^{2}$ & $\left(v_{i j^{-}} v_{j+}\right)^{2}$ & $\left(v_{i j^{-}} v_{j+}\right)^{2}$ & $\left(v_{i j^{-}} v_{j+}\right)^{2}$ & $\left(v_{i j^{-}} v_{j+}\right)^{2}$ \\
\hline 0.0051 & 0.0316 & 0.0018 & 0.0131 & 0.0000 \\
0.0000 & 0.0045 & 0.0018 & 0.0415 & 0.0017 \\
0.0051 & 0.0045 & 0.0018 & 0.0002 & 0.0426 \\
0.0051 & 0.0045 & 0.0018 & 0.0025 & 0.0119 \\
0.0051 & 0.0045 & 0.0018 & 0.0131 & 0.0017 \\
0.0000 & 0.0045 & 0.0462 & 0.0025 & 0.0017 \\
0.0000 & 0.1109 & 0.0018 & 0.0000 & 0.0426 \\
0.0051 & 0.0045 & 0.0018 & 0.0131 & 0.0017 \\
0.0000 & 0.0000 & 0.0462 & 0.0415 & 0.0000 \\
0.0000 & 0.0000 & 0.0018 & 0.1022 & 0.0017 \\
0.0051 & 0.0000 & 0.0462 & 0.0002 & 0.0119 \\
0.0000 & 0.0000 & 0.0000 & 0.0415 & 0.0426 \\
0.0000 & 0.0045 & 0.0018 & 0.0025 & 0.0426 \\
0.0000 & 0.0045 & 0.0018 & 0.0025 & 0.0426 \\
0.0051 & 0.0000 & 0.0000 & 0.0131 & 0.0426 \\
0.0051 & 0.0045 & 0.0018 & 0.0131 & 0.0017 \\
0.0051 & 0.0045 & 0.0018 & 0.0025 & 0.0119 \\
0.0051 & 0.0045 & 0.0018 & 0.0131 & 0.0017 \\
0.0000 & 0.0045 & 0.0462 & 0.0025 & 0.0017 \\
0.0051 & 0.0000 & 0.0462 & 0.0002 & 0.0119 \\
0.0000 & 0.0000 & 0.0000 & 0.0415 & 0.0426 \\
0.0000 & 0.0045 & 0.0462 & 0.0025 & 0.0017 \\
0.0000 & 0.1109 & 0.0018 & 0.0000 & 0.0426 \\
\hline
\end{tabular}

In the next step of TOPSIS, we calculate the sum of id+ and id- as presented in Table 7. 
Health Informatics- An International Journal (HIIJ) Vol.2,No.4,November 2013

Table 7. Sum of positive ideal and negative ideal

\begin{tabular}{|c|c|c|c|c|c|c|}
\hline $\begin{array}{c}\text { Sum } \\
\left(v_{i j^{-}} v_{j+}\right)^{2}\end{array}$ & d i + & SQRT & Sum of $\left(v_{i^{-}} v_{j-}\right)^{2}$ & d i- & SQRT & $\begin{array}{l}\text { Sum of } d i+ \\
\text { and } d \text { i- }\end{array}$ \\
\hline 0.10479 & d $1+$ & 0.32371 & 0.0516 & d $1-$ & 0.2272 & 0.15952 \\
\hline 0.13326 & d $2+$ & 0.36505 & 0.0494 & d 2- & 0.2223 & 0.16234 \\
\hline 0.13685 & d $3+$ & 0.36993 & 0.0542 & d 3- & 0.2329 & 0.18208 \\
\hline 0.13372 & d 4+ & 0.36568 & 0.0258 & d 4- & 0.1606 & 0.23171 \\
\hline 0.13624 & d $5+$ & 0.36911 & 0.0261 & d $5-$ & 0.1617 & 0.16234 \\
\hline 0.12718 & d $6+$ & 0.35662 & 0.0549 & d $6-$ & 0.2343 & 0.2465 \\
\hline 0.07631 & d $7+$ & 0.27624 & 0.1554 & d 7- & 0.3941 & 0.29222 \\
\hline 0.13624 & d $8+$ & 0.36911 & 0.0261 & d 8- & 0.1617 & 0.22009 \\
\hline 0.15880 & d 9+ & 0.39849 & 0.0877 & d 9- & 0.2961 & 0.24604 \\
\hline 0.18652 & d $10+$ & 0.43188 & 0.1057 & d $10-$ & 0.3251 & 0.18065 \\
\hline 0.15669 & d $11+$ & 0.39584 & 0.0634 & d $11-$ & 0.2518 & 0.18065 \\
\hline 0.16194 & d $12+$ & 0.40242 & 0.0841 & d $12-$ & 0.2900 & 0.22573 \\
\hline 0.12915 & d $13+$ & 0.35937 & 0.0515 & d 13- & 0.2269 & 0.16234 \\
\hline 0.12915 & d $14+$ & 0.35937 & 0.0515 & d 14- & 0.2269 & 0.15952 \\
\hline 0.16493 & d $15+$ & 0.40611 & 0.0608 & d $15-$ & 0.2467 & 0.16234 \\
\hline 0.13624 & d $16+$ & 0.36911 & 0.0261 & d $16-$ & 0.1617 & 0.18208 \\
\hline 0.13372 & d $17+$ & 0.36568 & 0.0258 & d $17-$ & 0.1606 & 0.22009 \\
\hline 0.13624 & d $18+$ & 0.36911 & 0.0261 & d $18-$ & 0.1617 & 0.24604 \\
\hline 0.12718 & d $19+$ & 0.35662 & 0.0549 & d $19-$ & 0.2343 & 0.18208 \\
\hline 0.15669 & d 20+ & 0.39584 & 0.0634 & d 20- & 0.2518 & 0.22667 \\
\hline 0.16194 & d $21+$ & 0.40242 & 0.0841 & d $21-$ & 0.2900 & 0.15952 \\
\hline 0.12718 & d $22+$ & 0.35662 & 0.0549 & d $22-$ & 0.2343 & 0.16234 \\
\hline 0.07127 & d $23+$ & 0.26696 & 0.1554 & d 23- & 0.3941 & 0.18208 \\
\hline
\end{tabular}

From the Table 7, di+ and di- stand for distance $\mathrm{i}$ from positive ideal and di- that stands for distance i from negative ideal, respectively. In the last step we rank 23 factors by calculating the distance between $\mathrm{A}_{\mathrm{i}}$ and ideal solution as following:

$c l i=\frac{d_{1}^{-}}{d_{1}^{-}+d_{1}^{+}} 0 \leq c l i \leq 1 \quad i=1,2, \ldots m$

Finally, in Table 8, we present the ranking of factors in the micro-level of ERMs adoption. The ranking in this table demonstrates that based on physicians' perception, ten important factors in micro level of electronic medical records adoption are patient choice, use strategies, ease of use, use intention, safety, communication, template, downtime and cost savings/profits. In addition, according to the ranking presented in Table 8 , the patient choice is ranked with a high priority and this confirms the result of work developed by Dennison et al., 2006. They showed that enhanced patient choice of appointment date and time significantly enhances the electronic surgical referral system can improve efficiency. Thus, it is important for adopter of EMRs that patient choice can play important role in their goals, mission and vision. 
Health Informatics- An International Journal (HIIJ) Vol.2,No.4,November 2013

Table 8. Final ranking of factors in the micro-level of ERMs adoption

\begin{tabular}{cccc}
\hline Sub-Factor & $\frac{d_{l}^{-}}{d_{i}^{-}+d_{I}^{+}}$ & Sorted & Priority \\
Patient choice & 0.412409 & 0.596163737 & 1 \\
Use strategies & 0.37848 & 0.587910613 & 2 \\
Ease of use & 0.386344 & 0.429469735 & 3 \\
Use intention & 0.305161 & 0.426294649 & 4 \\
Safety & 0.304629 & 0.418820947 & 5 \\
Communication & 0.3965 & 0.418820947 & 6 \\
Template & 0.587911 & 0.41240856 & 7 \\
Downtime & 0.304629 & 0.396500372 & 8 \\
Cost Savings/Profits & 0.426295 & 0.396500372 & 9 \\
Patient acceptance & 0.42947 & 0.396500372 & 10 \\
Interaction & 0.388796 & 0.388796245 & 11 \\
Maintenance cost & 0.418821 & 0.388796245 & 12 \\
Effectiveness & 0.387023 & 0.387023044 & 13 \\
Quality improvement & 0.387023 & 0.387023044 & 14 \\
Access & 0.377905 & 0.386344409 & 15 \\
Design performance & 0.304629 & 0.378479612 & 16 \\
Guidelines & 0.305161 & 0.37790475 & 17 \\
Content & 0.304629 & 0.305160751 & 18 \\
Efficiency & 0.3965 & 0.305160751 & 19 \\
Support & 0.388796 & 0.304628775 & 20 \\
Use pattern & 0.418821 & 0.304628775 & 21 \\
Care coordination & 0.3965 & 0.304628775 & 22 \\
Net cost & 0.596164 & 0.304628775 & 23 \\
\hline
\end{tabular}

\section{CONCLUSION}

The current study was done to develop the body of research related to technology adoption inside a professional environment in context of hospitals in private sector which could be applied in regard to public sector. This study has focused on micro-level factors which influence on EMR adoption and effect which is based on [12]. The limitation of the study confined the physicians who have not yet adopted the EMR or stop using this technology. The findings of the present study were used to address the adoption and effect of electronic medical records technology within the physician community in private hospitals in Malaysian. Physicians had very high perception means for the technology and showed that EMR would increase physician's performance. They have been and continue to be positively motivated to adopt and use the system. The TOPSIS Framework of Physician Adoption Model in Micro-Level, factors, finding discussed in this research give the essential components to make sense of EMR in the private hospitals.

\section{REFERENCES}

[1] Baron, R. J. (2007)."Quality improvement with an electronic health record: achievable, but not automatic." Annals of Internal Medicine 147(8): 549-552.

[2] Bolger-Harris, H., et al. (2008). "Using computer based templates for chronic disease management." Australian family physician 37(4): 285. 
Health Informatics- An International Journal (HIIJ) Vol.2,No.4,November 2013

[3] Booth, N., Robinson, P., \& Kohannejad, J. (2004). Identification of high-quality consultation practice in primary care: the effects of computer use on doctor-patient rapport. Informatics in primary care, 12(2), 75-83.

[4] Cauldwell, M. R., Beattie, C. E., Cox, B. M., Denby, W. J., Ede-Golightly, J. A., \& Linton, F. L. (2007). The impact of electronic patient records on workflow in general practice. Health informatics journal, 13(2), 155-160.

[5] Chee, H. L., \&Barraclough, S. (2007). Health care in Malaysia: the dynamics of provision, financing and access: Routledge.

[6] Christensen, T. and A. Grimsmo (2008). "Expectations for the next generation of electronic patient records in primary care: a triangulated study." Informatics in primary care 16(1): 21-28.

[7] Christian G. D. (2002). Electronic Medical Records Mark a Landmark Shift in Record Keeping.

[8] de Jong, J. D., Groenewegen, P. P., Spreeuwenberg, P., Westert, G. P., \& de Bakker, D. H. (2009). Do decision support systems influence variation in prescription? BMC health services research, $9(1)$, 20.

[9] DeLone, W. H. and E. R. McLean (1992). "Information systems success: the quest for the dependent variable." Information Systems Research 3(1): 60-95.

[10] Dennison, J., Eisen, S., Towers, M., \& Clark, C. I. (2006). An effective electronic surgical referral system. Annals of the Royal College of Surgeons of England, 88(6), 554.

[11] Frank, O. R., Litt, J. C., \& Beilby, J. J. (2004). Opportunistic electronic reminders: improving performance of preventive care in general practice. Australian family physician, 33(1-2), 87-90.

[12] Hamilton, W. T., Round, A. P., Sharp, D., \& Peters, T. J. (2003). The quality of record keeping in primary care: a comparison of computerised, paper and hybrid systems. The British Journal of General Practice, 53(497), 929.

[13] Hippisley-Cox, J., Pringle, M., Cater, R., Wynn, A., Hammersley, V., Coupland, C., . . Johnson, C. (2003). The electronic patient record in primary care-regression or progression? A cross sectional study. Bmj, 326(7404), 1439-1443.

[14] Hollingworth, W., Devine, E. B., Hansen, R. N., Lawless, N. M., Comstock, B. A., Wilson-Norton, J. L., . . . Sullivan, S. D. (2007). The Impact of e-Prescribing on Prescriber and Staff Time in Ambulatory Care Clinics: A Time-Motion Study. Journal of the American Medical Informatics Association, 14(6), 722-730.

[15] Hwang, C.L., Yoon, K., "Multiple Attributes Decision Making Methods and Applications", Springer, BerlinHeidelberg, 1981.

[16] Keshavjee, K., Troyan, S., Holbrook, A., \& VanderMolen, D. (2001). Measuring the success of electronic medical record implementation using electronic and survey data. Paper presented at the Proceedings of the AMIA Symposium.

[17] Kinn, J. W., O’Toole, M. F., Rowley, S. M., Marek, J. C., Bufalino, V. J., \& Brown, A. S. (2001). Effectiveness of the electronic medical record in cholesterol management in patients with coronary artery disease (Virtual Lipid Clinic). The American journal of cardiology, 88(2), 163-165.

[18] Lau, F., Hagens, S., \& Muttitt, S. (2006). A proposed benefits evaluation framework for health information systems in Canada. Healthcare quarterly (Toronto, Ont.), 10(1), 112-116, 118.

[19] Lau, F., Price, M., \& Keshavjee, K. (2011). From benefits evaluation to clinical adoption: making sense of health information system success in Canada. Healthc Q, 14(1), 39-45.

[20] Lau, F., Price, M., Boyd, J., Partridge, C., Bell, H., \&Raworth, R. (2012). Impact of electronic medical record on physician practice in office settings: a systematic review. BMC medical informatics and decision makin.12(1), 10.

[21] Linder, J. A., Ma, J., Bates, D. W., Middleton, B., \& Stafford, R. S. (2007). Electronic health record use and the quality of ambulatory care in the United States. Archives of Internal Medicine, 167(13), 1400-1405.

[22] Ludwick, D. and J. Doucette (2009). "Primary care physicians' experience with electronic medical records: barriers to implementation in a fee-for-service environment." International Journal of Telemedicine and Applications 2009: 2.

[23] Margalit, R. S., Roter, D., Dunevant, M. A., Larson, S., \& Reis, S. (2006). Electronic medical record use and physician-patient communication: an observational study of Israeli primary care encounters. Patient education and counseling, 61(1), 134-141.

[24] Martens, J. D., van der Weijden, T., Severens, J. L., de Clercq, P. A., De Bruijn, D., Kester, A. D., \& Winkens, R. A. (2007). The effect of computer reminders on GPs' prescribing behaviour: a clusterrandomised trial. International Journal of Medical Informatics, 76, S403-S416. 
[25] Miller, R. H., Sim, I., \& Newman, J. (2004). Electronic medical records in solo/small groups: a qualitative study of physician user types. Studies in health technology and informatics, 107(Pt 1), 658.

[26] Miller, R. H., Sim, I., \& Newman, J. (2004). Electronic medical records in solo/small groups: a qualitative study of physician user types. Studies in health technology and informatics, 107(Pt 1), 658.

[27] Miller, R. H., West, C., Brown, T. M., Sim, I., \& Ganchoff, C. (2005). The value of electronic health records in solo or small group practices. Health Affairs, 24(5), 1127-1137.

[28] Mitchell, E., McConnahie, A., \& Sullivan, F. (2003). Consultation computer use to improve management of chronic disease in general practice: a before and after study. Informatics in primary care, 11(2), 61-68.

[29] Montgomery, A. A., Fahey, T., Peters, T. J., MacIntosh, C., \& Sharp, D. J. (2000). Evaluation of computer based clinical decision support system and risk chart for management of hypertension in primary care: randomised controlled trial. Bmj, 320(7236), 686-690.

[30] Newby, D. A., Fryer, J. L., \& Henry, D. A. (2003). Effect of computerised prescribing on use of antibiotics. Medical journal of Australia, 178(5), 210-213. Onconomics, 21:4.

[31] Randeree, E. (2007). "Exploring physician adoption of EMRs: a multi-case analysis." Journal of medical systems 31(6): 489-496.

[32] Robinson, A. (2003). "Information technology creeps into rural general practice." Australian Health Review 26(1): 131-137.

[33] Schade, C. P., Sullivan, F. M., De Lusignan, S., \& Madeley, J. (2006). e-Prescribing, efficiency, quality: lessons from the computerization of UK family practice. Journal of the American Medical Informatics Association, 13(5), 470-475.

[34] Sood, S. P., Nwabueze, S. N., Mbarika, V. W. A., Prakash, N., Chatterjee, S., Ray, P., \& Mishra, S. (2008). Electronic medical records: a review comparing the challenges in developed and developing countries. Paper presented at the Hawaii International Conference on System Sciences, Proceedings of the 41st Annual.

[35] Tamblyn, R., Huang, A., Perreault, R., Jacques, A., Roy, D., Hanley, J., . . Laprise, R. (2003). The medical office of the 21st century (MOXXI): effectiveness of computerized decision-making support in reducing inappropriate prescribing in primary care. Canadian Medical Association Journal, 169(6), 549-556.

[36] Tamblyn, R., Huang, A., Taylor, L., Kawasumi, Y., Bartlett, G., Grad, R., . . Perreault, R. (2008). A randomized trial of the effectiveness of on-demand versus computer-triggered drug decision support in primary care. Journal of the American Medical Informatics Association, 15(4), 430-438.

[37] Vainiomäki, S., Kuusela, M., Vainiomäki, P., \& Rautava, P. (2008). The quality of electronic patient records in Finnish primary healthcare needs to be improved. Scandinavian journal of primary health care, 26(2), 117-122.

[38] Wager, K. A., Lee, F. W., White, A. W., Ward, D. M., \& Ornstein, S. M. (2000). Impact of an electronic medical record system on community-based primary care practices. The Journal of the American Board of Family Practice, 13(5), 338-348.

[39] Wells, S., Furness, S., Rafter, N., Horn, E., Whittaker, R., Stewart, A., Bramley, D. (2008). Integrated electronic decision support increases cardiovascular disease risk assessment four fold in routine primary care practice. European Journal of Cardiovascular Prevention \& Rehabilitation, 15(2), 173178.

[40] Hwang, C.L. and K. Yoon, 1981. Multiple Attributes Decision Making Methods and Applications. Springer, Berlin Heidelberg.

[41] Nilashi, M., Bagherifard, K., Ibrahim, O., Janahmadi, N., \& Ebrahimi, L. Ranking Parameters on Quality of Online Shopping Websites Using Multi-Criteria Method. Research Journal of Applied Sciences, 4(21): 4380-4396.

[42] M. Nilashi, K. Bagherifard, O. Ibrahim, N. Janahmadi and H. Alizadeh, "Multi-criteria approach to the evaluation of Malaysian government portal." Journal of Theoretical and Applied Information Technology, vol. 40, no. 2, pp. 194-201, 2012. 